REVISTA DE DERECHO UNED, NÚM. 26, 2020

\title{
EL CONTRATO DE FRANQUICIA EN LA PROPUESTA DE ANTEPROYECTO DE LEY DE CÓDIGO MERCANTIL TRAS EL DICTAMEN DEL CONSEJO DE ESTADO
}

\author{
THE FRANCHISE AGREEMENT IN THE PROPOSAL OF THE \\ DRAFT LAW OF THE COMMERCIAL CODE ISSUED AFTER THE \\ OPINION OF THE SPANISH STATE COUNCIL
}

\section{Guillermo Conde Gómez}

Abogado.

Doctorando investigador. Programa de Doctorado en Derecho y Ciencias Sociales. Universidad Nacional de Educación a Distancia (UNED).

Resumen: El presente trabajo aborda el análisis del contrato de franquicia a la luz de la regulación prevista para los contratos de distribución en los artículos 545-1 y ss. de la Propuesta de Anteproyecto de Ley de Código Mercantil tras el Dictamen del Consejo de Estado.

Pese a su gran importancia, nuestro ordenamiento jurídico carece actualmente de un régimen legal que regule un marco jurídico propio del contrato de franquicia, teniendo por tanto dicho contrato la consideración de atípico. No obstante, si bien la Ley 7/1996, de 15 de enero, de Ordenación del Comercio Minorista y el Real Decreto 201/2010, de 26 de febrero, por el que se regula el ejercicio de la actividad comercial en régimen de franquicia y la comunicación de datos al registro de franquiciadores, regulan algunos aspectos del contrato de franquicia en España, dichas regulaciones resultan del todo insuficientes, de tal manera que a día de hoy el contrato de franqui- 
cia continúa teniendo al Código Civil y al Código de Comercio como principales referencias normativas.

De esta manera, la regulación del contrato de franquicia prevista en la Propuesta de Anteproyecto de Ley de Código Mercantil tras el Dictamen del Consejo de Estado, pese a no ser el primer intento de regular el contrato de franquicia, de finalmente materializarse constituirá un importante avance en la regulación de dicha figura contractual en nuestro ordenamiento jurídico, aportando mayor seguridad jurídica al sector de la franquicia en España.

Abstract: This paper analyzes the franchise agreement in light of the regulation provided for distribution agreements in articles 545-1 et seq. of the Proposal of the Draft Law of the Commercial Code issued after the Opinion of the Spanish State Council.

Despite its great importance, our legal system currently lacks a legal regime that regulates a legal framework of the franchise agreement, therefore, said agreement is considered as atypical. However, although Law 7/1996, of January 15, on Retail Trade and Royal Decree 201/2010, of February 26, which regulates the exercise of commercial activity under the franchise regime and the communication of data to the franchisor registry, regulate some aspects of the franchise agreement in Spain, these regulations are completely insufficient, therefore to this day the franchise agreement continues to have the Spanish Civil Code and the Spanish Commercial Code as its main legal references.

Thus, the proposed regulation of the franchise agreement provided for in the Proposal of the Draft Law of the Commercial Code issued after the Opinion of the Spanish State Council, despite not being the first attempt to regulate the franchise agreement, if it finally occurs will constitute an important step forward in the regulation of such agreement in our legal system, providing greater legal certainty for the franchise sector in Spain.

Palabras clave castellano: Contrato de franquicia, franquiciador, franquiciado, indemnización por clientela, Propuesta de Anteproyecto de Ley de Código Mercantil tras el Dictamen del Consejo de Estado.

English keywords: Franchise agreement, franchisor, franchisee, customer's compensation, Proposal of the Draft Law of the Commercial Code issued after the Opinion of the Spanish State Council.

Recepción original: 6-2-2020

Aceptación original: 29-2020 
Sumario: I. Introducción. II. El Contrato de Franquicia en la Propuesta de Anteproyecto de Ley de Código Mercantil. II.A. Perfección del contrato. II.B. Obligaciones de las partes. II.C. Duración y extinción del contrato. III. El contrato de Master Franquicia en la Propuesta de Anteproyecto de Ley de Código Mercantil IV. Conclusiones.

\section{INTRODUCCIÓN.}

El presente trabajo aborda el análisis del contrato de franquicia a la luz de la regulación prevista en los artículos 545-1 a 545-23 de la Propuesta de la Sección Segunda de Derecho Mercantil del Anteproyecto de Ley de Código Mercantil tras el Dictamen del Consejo de Estado (en adelante, la "PALCM") en la cual se regulan los contratos de distribución comercial en general y el contrato de franquicia en particular ${ }^{1}$.

En este sentido, de entre las modalidades de los contratos de distribución comercial contempladas en la PALCM, en su art. 545-2, apartado f), se contempla el contrato de franquicia, siendo su definición la siguiente ${ }^{2}$ :

"El contrato de franquicia, por el cual el titular de la franquicia denominado franquiciador, cede al distribuidor, denominado franquiciado, el derecho a explotar en beneficio de éste un sistema de comercialización de bienes o servicios bajo los signos distintivos y la asistencia técnica permanente del franquiciador, a cambio de una compensación económica y del compromiso de ajustarse en todo momento a las reglas de actuación establecidas."

Las franquicias pueden ser fundamentalmente comerciales o industriales, siendo la franquicia comercial la única que entraría den-

1 Propuesta de la Sección Segunda, de Derecho Mercantil del Anteproyecto de Ley de Código Mercantil tras el Dictamen del Consejo de Estado. Ministerio de Justicia, Secretaría General Técnica. Madrid, marzo 2018. Se puede consultar su contenido en la página Web del Congreso: www.congreso.es.

2 ALONSO LEDESMA, Carmen. "La regulación de las obligaciones y contratos mercantiles en general en el Anteproyecto de Código Mercantil". En: Hacia un nuevo Código Mercantil. Ed. Thomson Reuters, Madrid 2014, pág. 1.169; PÉREZ-SERRABONA GONZÁLEZ, Francisco Javier. "Franquicia y contratos de distribución en el Anteproyecto de Código Mercantil". En: Estudios sobre el futuro Código Mercantil: Libro homenaje al profesor Rafael Illescas Ortiz. Universidad Carlos III de Madrid, Madrid 2015, págs. 1.667-1.686; GARCÍA HERRERA, Alicia. El impacto del tiempo en los contratos de franquicia y distribución exclusiva. Ed. Tirant lo Blanch, Valencia 2008, págs. 11 a 26. 
tro del ámbito de aplicación de la PALCM pues expresamente el artículo 545-3.b) excluye las franquicias industriales ${ }^{3}$.

El contrato de franquicia se configura como un tipo de contrato de distribución, de carácter bilateral y sinalagmático entre las partes al generar obligaciones para los contratantes (franquiciador y franquiciado $)^{4}$. Se establece de forma consensuada y las partes pueden exigir la forma escrita del mismo aunque no es obligatoria ${ }^{5}$, además, tiene carácter oneroso al establecerse el denominado canon. Asimismo, el contrato se establece en la mayoría de los casos de forma personalísima y su duración es de tracto sucesivo ${ }^{6}$.

Nuestro ordenamiento jurídico carece actualmente de un régimen legal que regule un marco jurídico propio del contrato de franquicia en particular y de los contratos de distribución comercial en general $^{7}$, siendo el Código Civil y el Código de Comercio sus principales referencias normativas ${ }^{8}$. No obstante lo anterior, el contrato de franquicia tiene una regulación específica en dos normas de nuestro ordenamiento jurídico:

(i) El artículo 62 de la Ley 7/1996, de 15 de enero, de Ordenación del Comercio Minorista (“LOCM"), el cual proporciona una definición del contrato de franquicia ("acuerdo o contrato por el que una empresa, denominada franquiciadora, cede a otra, denominada franquiciada, el derecho a la explotación de un sistema

3 Art. 545-2 f) frente al art. 545-3 b) de la Propuesta de la Sección Segunda, de Derecho Mercantil del Anteproyecto de Ley de Código Mercantil tras el Dictamen del Consejo de Estado. Ministerio de Justicia, Secretaría General Técnica. Madrid, marzo 2018. Se puede consultar su contenido en la página Web del Congreso: www. congreso.es.

4 PÉREZ-SERRABONA GONZÁLEZ, Francisco Javier. "Franquicia y contratos de distribución en el Anteproyecto de Código Mercantil”. En: Estudios sobre el futuro Código Mercantil: Libro homenaje al profesor Rafael Illescas Ortiz. Universidad Carlos III de Madrid, Madrid 2015, pág. 1.670.

5 Art. 545-5 de la Propuesta de la Sección Segunda, de Derecho Mercantil del Anteproyecto de Ley de Código Mercantil tras el Dictamen del Consejo de Estado. Ministerio de Justicia, Secretaría General Técnica. Madrid, marzo 2018. Se puede consultar su contenido en la página Web del Congreso: www.congreso.es.

6 PÉREZ-SERRABONA GONZÁLEZ, Francisco Javier. "Franquicia y contratos de distribución en el Anteproyecto de Código Mercantil". En: Estudios sobre el futuro Código Mercantil: Libro homenaje al profesor Rafael Illescas Ortiz. Universidad Carlos III de Madrid, Madrid 2015, pág. 1.670.

7 PELLISÉ DE URQUIZA, Cristina. Los Contratos de Distribución Comercial. Problemas de Derecho Internacional Privado en la Comunidad Europea. Ed. Bosch, Madrid 1999, pág.30.

8 Exposición de Motivos $\mathrm{n}^{\circ} \mathrm{I}$ del Proyecto de la Ley de Contratos de Distribución. Boletín Oficial de las Cortes Generales. Proyecto de Ley número 121/000138. 29 de junio de 2011. 
propio de comercialización de productos o servicios") y establece la obligación precontractual del franquiciador de hacer entregar al franquiciado con una antelación mínima de 20 días a la firma del contrato de franquicia la información esencial sobre la franquicia; $y$

(ii) El Real Decreto 201/2010, de 26 de febrero, por el que se regula el ejercicio de la actividad comercial en régimen de franquicia y la comunicación de datos al registro de franquiciadores, cuyo contenido ha quedado limitado únicamente a regular determinadas condiciones básicas para desarrollar la actividad de cesión de franquicias y, en particular, el desarrollo del artículo 62.2 de la LOCM en lo que a la información precontractual se refiere $^{9}$.

En lo que respecta a los distintos intentos de regular en nuestro ordenamiento jurídico los contratos de distribución comercial en general y el contrato de franquicia en particular, el 29 de junio de 2011 se presentó para su tramitación parlamentaria el Proyecto de Ley de Contratos de Distribución (el "PLCD”) que fue uno de los primeros intentos normativos en nuestro país para el establecimiento de un marco legal propio de los contratos de distribución ${ }^{10}$. No obstante, pese a que el Consejo de Ministros remitió a las Cortes Generales de España el PLCD, su tramitación parlamentaria no llegó a su fin.

Años más tarde, dichos intentos de regulación volvieron a estar en la agenda a través de la Propuesta de Código Mercantil elaborada por la Sección de Derecho Mercantil de la Comisión de Codificación dependiente del Ministerio de Justicia (la "PCM")11 y que al igual que el PLCD introducía una regulación del contrato de franquicia como tipo de los contratos de distribución ${ }^{12}$.

9 Los artículos 5 y ss. del Real Decreto 201/2010, de 26 de febrero, por el que se regula el ejercicio de la actividad comercial en régimen de franquicia y la comunicación de datos al registro de franquiciadores, en los cuales se regulaba el Registro de Franquiciadores, fueron derogados por el Real Decreto Ley 20/2018, de 7 de diciembre de medidas urgentes para el impulso de la competitividad económica en el sector de la industria y el comercio en España («B.O.E.» 8 diciembre).

10 Proyecto de la Ley de Contratos de Distribución. Boletín Oficial de las Cortes Generales. Proyecto de Ley número 121/000138. 29 de junio de 2011. Se puede consultar su contenido en la página Web del Congreso: www.congreso.es.

11 Propuesta de la Sección Segunda, de Derecho Mercantil del Anteproyecto de Ley de Código Mercantil tras el Dictamen del Consejo de Estado. Ministerio de Justicia, Secretaría General Técnica. Madrid, marzo 2018. Se puede consultar su contenido en la página Web del Congreso: www.congreso.es.

12 La Sección Segunda de Derecho Mercantil de la Comisión General de Codificación, recibió el 7 de noviembre de 2006, el encargo de elaborar un nuevo Código

(C) UNED. Revista de Derecho UNED, núm. 26, 2020 
No obstante, el 30 de mayo de 2014, tras recibir el correspondiente informe del entonces Ministro de Justicia, D. Alberto RuízGallardón, el Consejo de Ministros dio luz verde a la PCM, convirtiéndolo en el Anteproyecto de Ley del Código Mercantil (“ALCM") ${ }^{13}$ y cuyo texto finalmente aprobado por el Consejo de Ministros carecía de regulación legal para el contrato de franquicia así como para el resto de contratos de distribución.

Finalmente, en el mes de marzo de 2018, la Sección Segunda de Derecho Mercantil de la Comisión de Codificación dependiente del Ministerio de Justicia, publica la PALCM tras el dictamen que del ALCM realizó el Consejo de Estado ${ }^{14}$ y en la cual se recupera la regulación de los contratos de distribución en general y el contrato de franquicia en particular con algunas modificaciones respecto de la regulación prevista en la $\mathrm{PCM}^{15}$.

Así, a día de hoy, contamos nuevamente con una propuesta de regulación de los contratos de distribución en general y del contrato de franquicia en particular, la cual, si bien no es todo lo exhaustiva que cabría esperar dadas las pretensiones que planteaba la PCM, sin duda es un nuevo paso por establecer en el ordenamiento jurídico español una regulación de los contratos de distribución comercial y, por ende, del propio contrato de franquicia.

\section{EL CONTRATO DE FRANQUICIA EN LA PROPUESTA DE ANTEPROYECTO DE LEY DE CÓDIGO MERCANTIL.}

La regulación general de los contratos de distribución comercial se encuentra contenida en el Capítulo V, Título IV, Libro Quinto de la PALCM. El Libro Quinto de la PALCM regula los contratos mercantiles en particular y el Título IV de dicho Libro regula los denominados contratos de colaboración, de tal manera que los contratos de distribución en general y el contrato de franquicia en particular comparten título con contratos afines en algunos aspectos como son

del entonces Ministro de Justicia, Juan Fernando López Aguilar. Con cerca de 1.900 artículos, recopila e integra en un único texto prácticamente toda la legislación mercantil e incorpora materias que hasta ahora carecían de regulación legal.

13 Anteproyecto de Ley del Código Mercantil. Ministerio de Justicia. Ministerio de Economía y Competitividad. 29 de enero de 2015. Se puede consultar su contenido en la página Web del Congreso: www.congreso.es.

14 Dictamen del Consejo de Estado de fecha 29 de enero de 2015. Ref. 837/2014.

15 Propuesta de la Sección Segunda, de Derecho Mercantil del Anteproyecto de Ley de Código Mercantil tras el Dictamen del Consejo de Estado. Ministerio de Justicia, Secretaría General Técnica. Madrid, marzo 2018. Se puede consultar su contenido en la página Web del Congreso: www.congreso.es. 
el contrato de comisión, agencia, estimatorio, mediación mercantil y contrato de participación.

De esta manera, el contrato de franquicia se regula en la PALCM como una modalidad de contrato de distribución, compartiendo regulación con las restantes modalidades, como son; (i) el contrato de compra y venta en exclusiva; (ii) el contrato de distribución autorizada; (iii) el contrato de distribución selectiva y; (iv) el contrato de concesión mercantil ${ }^{16}$.

La inclusión en la PALCM del contrato de franquicia como categoría de contrato de distribución no está exenta de dudas por cuanto supone otorgar a la función de distribución la condición de elemento definitorio del contrato de franquicia, función que, dependiendo del tipo de franquicia ante el que nos encontremos, puede darse o no.

A este respecto, no debe de olvidarse que el objeto principal del contrato de franquicia es la de conceder al franquiciado el derecho de explotar la franquicia para comercializar determinados bienes y servicios, pudiendo existir o no la obligación de distribuir los bienes del franquiciador, de tal manera que en términos generales no se puede considerar la función de distribución como definitoria del contrato de franquicia ${ }^{17}$.

Así, al regular la PALCM el contrato de franquicia como categoría de los contratos de distribución puede dar lugar a interpretarse que dicha regulación únicamente aplicaría para aquellos contratos de franquicia en los que exista una función de distribución, dejando fuera de dicha regulación a los restantes contratos de franquicia que no tuvieran dicha función. Sin embargo, no debe de obviarse que la regulación que de los contratos mercantiles y obligaciones en general se realiza en el Libro IV de la PALCM sí sería de aplicación a dichos contratos de franquicia dado su carácter mercantil.

No obstante, la anterior afirmación resultaría difícil de sostener dada la definición del contrato de franquicia utilizada en el artículo 545-2.f) de la PALCM, en la cual no se realiza alusión alguna a la

16 Art. 545-2 de la Propuesta de la Sección Segunda, de Derecho Mercantil del Anteproyecto de Ley de Código Mercantil tras el Dictamen del Consejo de Estado. Ministerio de Justicia, Secretaría General Técnica. Madrid, marzo 2018. Se puede consultar su contenido en la página Web del Congreso: www.congreso.es.

17 NAVARRO MÁÑEZ, Miguel y ARRIBAS OCHOA, Carlos. "La Aplicación a la Franquicia del Régimen Propuesto para el Contrato de Distribución: Una Valoración Crítica". En: La reforma de los contratos de distribución comercial. Ed. La Ley, Madrid 2013, pág. 92. 
función de distribución y se limita a definir el contrato de franquicia como el derecho a explotar un sistema de comercialización de bienes y servicios bajo los signos distintivos y la asistencia técnica del franquiciador.

A la vista de lo anterior, son múltiples las dudas que surgen al respecto de la aplicación o no de la regulación de la PALCM a aquellos contratos de franquicia que no tengan función de distribución, sin duda, estos interrogantes, de no ser resueltos por el legislador en caso de continuar adelante con la tramitación legislativa de la PALCM, generarán inseguridad jurídica en el sistema de franquicia, por lo que resulta necesario que dichas cuestiones sean resueltas en el trámite parlamentario de la futura Ley de Código Mercantil.

\section{II.A. Perfección del contrato.}

Desde el momento en que surge la iniciativa de celebrar un contrato de franquicia hasta que éste se perfecciona deben llevarse a cabo diferentes acciones previas tendentes a la perfección del contrato, las cuales aparecen reguladas en los artículos 545-5 y 545-6 de la PALCM además de en las diferentes normas aplicables a las obligaciones y contratos mercantiles en general reguladas en el Libro IV de la PALCM ${ }^{18}$.

\section{II.A.1. Formalización por escrito.}

La formalización por escrito del contrato de franquicia no es un requisito indispensable para su perfeccionamiento de acuerdo con lo establecido en el artículo 545-5 de la PALCM ${ }^{19}$. No obstante, que el contrato no se formalice de forma escrita puede derivar en problemas interpretativos acerca del clausulado que lo compone, entre los problemas que se pueden dar en la práctica común nos encontramos, entre otros, con los objetivos mínimos de compra, indemnización por clientela y amortización de inversiones, entre otros.

18 SCHULZE, Reiner. "Deberes precontractuales y conclusión del contrato en el Derecho Contractual Europeo”. En: Textos básicos de Derecho privado europeo. Ed. Marcial Pons, Madrid 2002, págs. 31-58.; SACRISTÁN BERGIA, Fernando. "Tratos preliminares y contratos de distribución". En: Los contratos de distribución comercial. Ed. La Ley, Madrid 2010, págs. 427-451.

19 PLANA PALUZIE, Alex. "El contrato de distribución en la propuesta de Código Mercantil”. Revista Aranzadi Doctrinal, n 8, diciembre 2013, págs. 67-82. 
El que la PALCM no haya exigido la obligatoriedad de la formalización por escrito del contrato de franquicia entendemos que supone un error por cuanto son múltiples los contenidos e información que deben de enviarse y conocer el franquiciado de forma anticipada a la formalización del contrato para que luego no sea obligatorio plasmar por escrito la forma en que se obligan franquiciador y franquiciado.

La formalización por escrito de este contrato sirve para que ambas partes conozcan sus derechos y obligaciones y sobre todo para evitar las posibles cláusulas abusivas o motivos de nulidad que pueda contener el contrato de franquicia, así como evitar interpretaciones diversas sobre su ejecución o cumplimiento del mismo.

\section{II.A.2. Información precontractual.}

La PALCM en su art.545-6 establece una serie de deberes que deben cumplirse con anterioridad a la celebración del contrato de franquicia y que se traducen en la obligación de las partes de suministrarse determinada información.

En particular, las partes se deben de facilitar la siguiente información: a) la identificación de los contratantes y los datos económicos y jurídicos de sus establecimientos mercantiles; b) las características de la actividad de distribución, titularidad de los signos distintivos y estructura y extensión de la red de distribución del franquiciador en España; c) los elementos y contenido esenciales del contrato y, en particular, los derechos y obligaciones de las partes, los pactos de exclusividad, las restricciones impuestas a la actividad, la duración del contrato, las causas y condiciones de resolución y los efectos de la extinción del contrato ${ }^{20}$. Esta información es especialmente relevante puesto que va a ser la base a partir de la cual se va a regular el futuro contrato de franquicia ${ }^{21}$.

Con carácter adicional a lo establecido en el artículo 545-6 de la PALCM, debe de tomarse en consideración lo estipulado en el artí-

20 Art. 545-6.1 de la Propuesta de la Sección Segunda, de Derecho Mercantil del Anteproyecto de Ley de Código Mercantil tras el Dictamen del Consejo de Estado. Ministerio de Justicia, Secretaría General Técnica. Madrid, marzo 2018. Se puede consultar su contenido en la página Web del Congreso: www.congreso.es.

21 SACRISTÁN BERGIA, Fernando. "Tratos preliminares y contratos de distribución”. En: Los contratos de distribución comercial. Ed. La Ley, Madrid 2010, pág. 449; SCHULZE, Reiner. "Deberes precontractuales y conclusión del contrato en el Derecho Contractual Europeo". En: Textos básicos de Derecho privado europeo. Ed. Marcial Pons, Madrid 2002, pág.32. 
culo 62.2 de la LOCM, el cual establece que con una antelación mínima de 20 días a la firma de cualquier contrato o precontrato de franquicia o entrega por parte del futuro franquiciado al franquiciador de cualquier pago, el franquiciador deberá haber entregado al futuro franquiciado por escrito la información necesaria para que pueda decidir libremente y con conocimiento de causa su incorporación a la red de franquicia y, en especial, los datos principales de identificación del franquiciador, descripción del sector de actividad del negocio objeto de franquicia, contenido y características de la franquicia y de su explotación, estructura y extensión de la red y elementos esenciales del acuerdo de franquicia.

Junto con el artículo 62.2. de la LOCM debemos también de tomar en consideración el artículo 3 del Real Decreto 201/2010, de 26 de febrero, por el que se regula el ejercicio de la actividad comercial en régimen de franquicia, que desarrolla el contenido del artículo 62.2 de la LOCM y que de manera similar al artículo 545-6 de la PALCM establece la obligación del franquiciador de suministrar al franquiciado con determinada información y con una antelación mínima de veinte días hábiles ${ }^{22}$.

22 El artículo 3 del Real Decreto 201/2010, de 26 de febrero, por el que se regula el ejercicio de la actividad comercial en régimen de franquicia, que desarrolla el contenido del artículo 62.2 de la LOCM exige el suministro al franquiciado de la siguiente información:

“a) Datos de identificación del franquiciador: nombre o razón social, domicilio y datos de inscripción en el registro de franquiciadores, así como, cuando se trate de una compañía mercantil, capital social recogido en el último balance, con expresión de si se halla totalmente desembolsado o en qué proporción y datos de inscripción en el Registro Mercantil, cuando proceda.

Cuando se trate de franquiciadores extranjeros, además, los datos de inscripción en los registros de franquiciadores a que vengan obligados, de acuerdo con las leyes de su país o Estado de origen. De tratarse de franquiciado principal se incluirán, además, las circunstancias anteriores respecto de su propio franquiciador.

b) Acreditación de tener concedido para España, y en vigor, el título de propiedad o licencia de uso de la marca y signos distintivos de la entidad franquiciadora, y de los eventuales recursos judiciales interpuestos que puedan afectar a la titularidad o al uso de la marca, si los hubiere, con expresión, en todo caso, de la duración de la licencia.

c) Descripción general del sector de actividad objeto del negocio de franquicia, que abarcará los datos más importantes de aquél.

d) Experiencia de la empresa franquiciadora, que incluirá, entre otros datos, la fecha de creación de la empresa, las principales etapas de su evolución y el desarrollo de la red franquiciada.

e) Contenido y características de la franquicia y de su explotación, que comprenderá una explicación general del sistema del negocio objeto de la franquicia, las características del saber hacer y de la asistencia comercial o técnica permanente que el franquiciador suministrará a sus franquiciados, así como una estimación de las inversiones y gastos necesarios para la puesta en marcha de un negocio tipo. En el caso de que el franquiciador haga entrega al potencial franquiciado individual de previsiones 
La información que se debe entregar debe basarse en el deber fundamental de buena fe entre las partes para evitar desequilibrios entre ellas ${ }^{23}$ puesto que así se garantiza un consentimiento adecuado al caso concreto y además, de acuerdo con lo establecido en el artículo 545-6.3 de la PALCM, las Partes deben de mantener una absoluta confidencialidad sobre la información recibida, aún en caso de que no llegara a celebrarse el contrato.

El conocimiento de la información precontractual de manera anticipada interesa a ambas partes, al franquiciador le interesa conocer de manera anticipada las características o potencial del franquiciado para una correcta selección del mismo de acuerdo a sus intereses, la zona a trabajar o si se reúnen los requisitos para ingresar en su red de franquicia, y respecto al franquiciado, le interesa conocer las características y condiciones de la franquicia para poder valorar en su conjunto la misma.

En el caso de que no se llegase a celebrar el contrato de franquicia, la parte que no hubiese cumplido con los deberes de información contenidos en el art. 545-5 de la PALCM deberá responder de los daños y perjuicios causados a la otra parte producidos por el incumplimiento ${ }^{24}$.

La buena fe de las partes se entenderá quebrantada cuando alguna de las partes haya silenciado o deformado la información a sabiendas o debiendo saber que de haberlo conocido la otra parte ésta

de cifras de ventas o resultados de explotación del negocio, éstas deberán estar basadas en experiencias o estudios, que estén suficientemente fundamentados.

f) Estructura y extensión de la red en España, que incluirá la forma de organización de la red de franquicia y el número de establecimientos implantados en España, distinguiendo los explotados directamente por el franquiciador de los que operen bajo el régimen de cesión de franquicia, con indicación de la población en que se encuentren ubicados y el número de franquiciados que hayan dejado de pertenecer a la red en España en los dos últimos años, con expresión de si el cese se produjo por expiración del término contractual o por otras causas de extinción.

g) Elementos esenciales del acuerdo de franquicia, que recogerá los derechos y obligaciones de las respectivas partes, duración del contrato, condiciones de resolución y, en su caso, de renovación del mismo, contraprestaciones económicas, pactos de exclusivas, y limitaciones a la libre disponibilidad del franquiciado del negocio objeto de franquicia."

${ }^{23}$ CRUZ RIVERO, Diego. "La regulación proyectada (y fracasada) de los contratos de distribución. El proyecto de Ley de contratos de distribución y la propuesta de Código Mercantil". En: Estudios sobre el futuro Código Mercantil: Libro homenaje al profesor Rafael Illescas Ortiz. Universidad Carlos III de Madrid, Madrid 2015, págs. 1.262-1.288.

24 JARNE MUÑOZ, Pablo. "La responsabilidad precontractual en el sector de la Distribución comercial". Revista de Derecho de la Competencia y la Distribución, ${ }^{\circ}$ 13, 2013, págs. 51-80.

(c) UNED. Revista de Derecho UNED, núm. 26, 2020 
no habría prestado su consentimiento ${ }^{25}$. No obstante, siempre cabe la prueba en contrario de todas estas alegaciones.

\section{II.B. Obligaciones de las partes.}

Los artículos 545-7 a 545-9 de la PALCM regulan el régimen general de obligaciones asumidas por las partes de todo contrato de distribución, aplicable, con las limitaciones antes mencionadas, al contrato de franquicia.

Junto con estos artículos debemos de destacar lo preceptuado en el artículo 545-17 de la PALCM, aplicable en exclusiva al contrato de franquicia, el cual establece, por un lado, obligaciones particulares para el franquiciador, como es la transmisión del know how y la prestación de asistencia técnica al franquiciado y, por otro lado, establece obligaciones particulares para el franquiciado, como es el pago del canon, la no divulgación de aquellos secretos transmitidos por el franquiciador y a comunicar al franquiciador las violaciones de los derechos de propiedad intelectual o industrial que se produzcan en su territorio de actuación.

Como ya mencionamos con anterioridad, entendemos que el régimen general de obligaciones previstas en los artículos 545-7 a 545-9 de la PALCM será de aplicación en su totalidad al contrato de franquicia cuando exista una distribución de bienes o servicios, pues en aquellos casos en los cuales el concreto contrato de franquicia no implique una actividad de distribución algunos de dichos artículos no podrían ser de aplicación.

En cualquier caso, franquiciador y franquiciado deben de establecer cuáles son los términos y condiciones esenciales del contrato para poder determinar el alcance de sus obligaciones. Estos términos y condiciones pueden consistir en regular los objetivos comerciales, el precio recomendado de los productos o servicios, el importe y forma de pago del canon de franquicia, los signos distintivos de la marca o la zona de exclusividad, entre otros, aunque las partes pueden establecer cualquier otro elemento esencial del contrato al

25 RONCERO SÁNCHEZ, Antonio. "Deberes precontractuales de información (A propósito del régimen propuesto en el Proyecto de Ley de contratos de distribución de 29 de junio de 2011)". En: La Reforma de los Contratos de Distribución Comercial. Ed. La Ley, Madrid 2013, pág. 140. 
no tener un carácter regulado completamente y otorgar la PALCM dosis de autonomía a los contratantes en el marco de la buena $\mathrm{fe}^{26}$.

\section{II.B.1. Obligaciones del franquiciador.}

El franquiciador tiene como obligación esencial la cesión al franquiciado del derecho de explotación sobre la franquicia, obligación que no consiste en una simple autorización para poder explotar la franquicia pues va mucho más allá, el franquiciador debe de poner a disposición del franquiciado los elementos materiales e inmateriales necesarios para que el franquiciado pueda explotar el modelo de negocio de la franquicia, lo que implica; (i) la licencia de uso de las marcas y demás signos distintivos de la franquicia; (ii) la transmisión del know how y, (iii) la prestación de formación y asistencia comercial y/o técnica ${ }^{27}$.

Así, el artículo 545-17.1 de la PALCM establece la obligación del franquiciador de comunicar al franquiciado los conocimientos secretos para poder desarrollar el negocio (transmisión del know how) y a prestarle la asistencia técnica y comercial requerida, pero nada dice ni el artículo 545-17.1 ni los artículos 545-7 a 545-9 de la PALCM al respecto de la obligación del franquiciador de ceder los signos distintivos de la franquicia al franquiciado, se debe de acudir a la propia definición del contrato de franquicia prevista en el artículo 545-2.f) para confirmar la existencia, a nuestro entender, de dicha obligación en la PALCM:

"El contrato de franquicia, por el cual el titular de la franquicia, denominado franquiciador, cede al distribuidor, denominado franquiciado, el derecho a explotar en beneficio de éste un sistema de comercialización de bienes o servicios bajo los signos distintivos y la asistencia técnica permanente del franquiciador, a cambio de una compensación económica y del compromiso de ajustarse en todo momento a las reglas de actuación establecidas."

Conforme a dicha definición, entendemos que la PALCM debería de recoger en su artículo 545-17.1 la obligación del franquiciador de ceder los signos distintivos al franquiciado pues de lo contrario se

26 GRAS SAGRERA, Jordi. "Los contratos de distribución y la resolución de conflictos: jurisdicción y arbitraje”. En: Los contratos de distribución comercial. Novedades legislativas y jurisprudenciales. Ed. Tirant lo Blanch, Valencia 2010, págs. 255 y ss.

27 MARTí MIRAVALLS, Jaume. "El Contrato de Franquicia”. En: Los Contratos de Distribución Comercial: Novedades legislativas y jurisprudenciales. Ed. Tirant lo Blanch, Valencia 2010, pág. 103. 
estaría obviando una de las obligaciones a nuestro juicio fundamentales de todo contrato de franquicia como es la cesión de los signos distintivos.

En lo que respecta a las obligaciones exigibles al franquiciador en el marco de la distribución de bienes y servicios previstas en los artículos 545-7 a 545-9 de la PALCM, estas se pueden resumir en las siguientes:

a) Obligación de suministro.

El artículo 545-8.1 de la PALCM establece la obligación del franquiciador de suministrar al franquiciado los bienes y servicios objeto de la franquicia, obligación que es básica de toda franquicia en la que exista distribución de bienes o servicios ${ }^{28}$. Así, en cada contrato de franquicia se determinará la forma en la que el franquiciador suministrará al franquiciado, los plazos de envío y recepción, las formas de comunicarse entre las partes, el número de unidades, etc.

b) Obligaciones de información.

El artículo 545-8.2 de la PALCM establece la obligación del franquiciador de suministrar al franquiciado información al respecto de los precios y tarifas de adquisición de los productos o servicios objeto de distribución con suficiente antelación. Mediante esta obligación el franquiciado puede conocer los precios de los productos y servicios a distribuir a los efectos de poder negociar con el franquiciador las condiciones de venta así como poder calcular los márgenes de beneficio en la venta de dichos productos y servicios a los clientes finales.

Asimismo, la segunda de las obligaciones de información asumidas por el franquiciador la encontramos en el artículo 545-8.4 de la PALCM y en virtud de la cual el franquiciador se obliga a mantener informado al franquiciado con la mayor antelación posible de cualesquiera hechos que puedan afectar a la distribución de los productos y servicios. La finalidad de esta obligación es evidente, el franquiciado realiza inversiones y compromisos importantes por la distribución de los productos y servicios del franquiciador por lo que tiene toda su lógica que cualquier circunstancia que pueda ocurrir que afecte a dicha distribución sea puesta en conocimiento con la mayor antelación en manos del franquiciado.

28 CALAVIA MOLINERO, José Manuel. "El contrato de distribución en exclusiva". En: Los contratos de distribución comercial. Novedades legislativas y jurisprudenciales. Ed. Tirant lo Blanch, Valencia 2010, págs. 69 y ss. 
c) Deber de previsión.

De conformidad con lo preceptuado en el artículo 545-8.3 de la PALCM, el franquiciador tiene la obligación de mantener disponibles para su entrega al franquiciado el número de unidades de producto o elementos de prestación del servicio cuando éste se los solicite y conforme el precio, número, calidad y condiciones convenidas en el contrato de franquicia ${ }^{29}$.

Este deber de previsión conlleva que se debe de establecer en el contrato de franquicia cuál es el suministro habitual. Puede darse el caso de que en ciertos periodos de tiempo el suministro aumente pero que ambas partes pasado un tiempo ya contemplen dichos supuestos como habituales, puesto que pueden haber periodos concretos de mayor consumo ${ }^{30}$.

\section{II.B.2. Obligaciones del franquiciado.}

Al igual que ocurre con las obligaciones del franquiciador, los artículos 545-7 a 545-9 de la PALCM no regulan las obligaciones esenciales del franquiciado bajo el contrato de franquicia pues éstas obligaciones son reguladas en el artículo 545-17.2 de la PALCM. Los artículos 545-7 a 545-9 establecen las obligaciones generales aplicables a todos los contratos de distribución, franquicia incluida y que, por tanto, tal y como expusimos anteriormente, muchas de ellas serían únicamente aplicables en aquellos casos en los que la franquicia conlleve una actividad de distribución.

Dicho lo anterior, el franquiciado tiene como obligaciones principales el pago del canon de entrada a la franquicia así como el pago de los royalties y el canon de publicidad. En este sentido, el artículo 545-17.2 de la PALCM regula la obligación del franquiciado de pagar la cuota y el canon de acceso a la franquicia estipulados.

Si bien la naturaleza jurídica del canon de entrada es discutida por nuestra doctrina, la mayor parte de ella considera que dicho ca-

29 LÓPEZ RODRÍGUEZ, Ana Mercedes. "El contrato de distribución exclusiva o concesión comercial como contrato de prestación de servicios a efectos de la aplicación del foro conflictual del Reglamento Bruselas I. Comentario a la STSH de 19 de diciembre de 2013 (Corman-Collins S.A)”. Revista de la Unión Europea. N ${ }^{\circ}$ 13, 2014, págs. 35-42.

30 GRAS SAGRERA, Jordi. "Los contratos de distribución y la resolución de conflictos: jurisdicción y arbitraje". En: Los contratos de distribución comercial. Novedades legislativas y jurisprudenciales. Ed. Tirant lo Blanch, Valencia 2010, págs.76. y ss

(c) UNED. Revista de Derecho UNED, núm. 26, 2020 
non tiene como finalidad el retribuir al franquiciador el acceso a la red de franquicia ${ }^{31}$.

En lo que respecta al pago de los royalties o cánones periódicos, estos tienen como objeto el satisfacer el derecho a explotar el modelo de negocio de franquicia mientras dure el contrato, pudiendo pactar las partes la periodicidad del devengo y pago de dichos cánones.

Es de destacar que la PALCM nada dice al respecto del pago del canon por el uso de los signos distintivos, pese a que, de conformidad con lo previsto en el artículo 545-2.f), la explotación del negocio de franquicia requiere necesariamente de la cesión de uso de estos. A nuestro juicio, si bien convendría su regulación en la PALCM, esto es coherente con la falta de regulación específica de la obligación del franquiciador de ceder el uso de los signos distintivos en la PALCM tal y como vimos anteriormente.

Junto con las obligaciones económicas antes mencionadas, el franquiciado asume asimismo como compromiso esencial con el franquiciador el explotar la franquicia de conformidad con el modelo predeterminado por el franquiciador. El artículo 545-17.2 de la PALCM no prevé esta obligación a la hora de regular las obligaciones particulares del contrato de franquicia, para ello debemos de acudir a la propia definición del contrato de franquicia prevista en el artículo 545-2 f) de la PALCM, el cual establece el compromiso del franquiciado de ajustarse en todo momento a las reglas de actuación establecidas. Resulta llamativo que tratándose de una obligación esencial del franquiciado, el artículo 545-17.2 de la PALCM no la haya contemplado, lo cual se echa en falta.

La importancia de esta obligación estriba en que limita el modo de actuar del franquiciado pues debe de desarrollar el negocio dentro de los límites y pautas estipuladas por el franquiciador, así como bajo la tutela de éste, todo ello, con el objeto de proteger la reputación y el goodwill de la franquicia.

Junto con las anteriores obligaciones se destaca también como obligación principal del contrato de franquicia la obligación del franquiciado a mantener confidencialidad respecto del know how transmitido por el franquiciador, lo cual se justifica en que tanto al franquiciador como al franquiciado les interesa que el know how no

31 MARTÍ MIRAVALLS, Jaume. "El Contrato de Franquicia". En: Los Contratos de Distribución Comercial: Novedades legislativas y jurisprudenciales. Ed. Tirant lo Blanch, Valencia 2010, págs. 111 y ss. 
sea transmitido a terceros, pues de lo contrario estos podrían replicar el modelo de franquicia sin pertenecer a la misma respetando sus límites y modos de actuación.

Finalmente, el artículo 545-17.2 de la PALCM establece la obligación del franquiciado de informar al franquiciador de las violaciones de los derechos de propiedad intelectual e industrial que se produzcan en su territorio, obligación que entendemos coherente con la necesidad de salvaguardar el goodwill y la reputación de la franquicia.

Por lo demás, en lo que respecta a las obligaciones exigibles al franquiciado en el marco de la distribución de los bienes y servicios previstas en los artículos 545-7 a 545-9 de la PALCM, pueden resumirse en las siguientes:

a) Obligaciones de adquirir y comercializar.

El artículo 545-9.1 de la PALCM establece la obligación del franquiciado de adquirir del franquiciador o de aquella persona designada por éste, los bienes y servicios para su comercialización o reventa, contando para ello con una organización empresarial suficiente y desarrollar una actividad comercial adecuada para promover la venta de dichos bienes y servicios.

Así, el franquiciado asume la obligación principal de satisfacer el precio pactado al franquiciador por la entrega de los bienes y servicios objeto del contrato, el cual deberá satisfacerse en el lugar y momento que las partes hayan establecido. El precio de adquisición debe de quedar fijado entre las partes así como las formas de actualización periódica del mismo si así lo estipulan. En defecto de que las partes no establecieran el precio ni los medios para determinarlo, cobra gran importancia la documentación que las partes se hayan comunicado con anterioridad a la celebración del contrato para al menos poseer un punto de referencia sobre los precios del mercado y la actividad comercial con el proveedor en situaciones análogas.

En cuanto al precio de venta al público, al tratarse de un acuerdo entre empresas "vertical" entre el franquiciador y el franquiciado, el precio de venta al público consistirá en el que fije finalmente el franquiciado ${ }^{32}$. Así, entre las conductas prohibidas se incluye la posibilidad de que el franquiciador establezca los precios de venta al

32 En estos casos no cabe acogerse al régimen de exención de categorías establecido en el Reglamento 330/2010 de 20 de abril de 2010 relativo a la aplicación del artículo 101, apartado 3, del Tratado de Funcionamiento de la Unión Europea a determinadas categorías de acuerdos verticales y prácticas concertadas. DOCE 23.04.2010. L 102/1. 
público, pudiendo solamente el franquiciador fijar determinados márgenes de venta con los que el franquiciado puede jugar o un precio máximo orientativo de venta ${ }^{33}$.

Por otro lado, el artículo 545-9.2 de la PACLM establece la obligación del franquiciado de comercializar los bienes y servicios del franquiciador, estableciendo que dicha obligación deberá de realizarse sin menoscabar el prestigio del franquiciador, respetando su marca y presentación y ajustándose en todo momento al sistema de distribución establecido por el franquiciador.

La comercialización de los bienes y servicios del franquiciador implica la realización de determinadas acciones comerciales y promocionales por parte del franquiciado quien, a través de dichas acciones, pretende la mayor difusión de los productos y servicios en el territorio o territorios de su influencia.

Para llevar a cabo estas acciones de comercialización el franquiciado deberá de establecer diferentes tipos de estrategias, todas ellas encaminadas a la mayor difusión de los bienes y servicios, estas estrategias podrán consistir en acciones focalizadas en los propios productos o servicios, en el precio de los mismos, en las fórmulas de distribución o en acciones publicitarias y de comunicación, estando limitadas a las directrices que el franquiciador pueda imponer para adaptarse a los estándares y fórmulas de comercialización establecidas en la franquicia.

b) Llevanza de registros contables auxiliares.

El artículo 545-9.3 establece la obligación del franquiciado de llevanza de unos registros contables auxiliares relativos a la actividad que constituyan el objeto del contrato, teniendo derecho del franquiciador a examinarlos. Para ello, las partes deben de establecer la forma en que el franquiciador puede acceder de forma periódica o en determinas ocasiones al análisis y examen de estos registros.

33 Sentencia del Juzgado de lo Mercantil de Madrid de 3 de septiembre de 2007, $n^{\circ}$. 102/2005 (AC 2008/177) que en su FJ CUARTO expresa:

“(...) entre las conductas intolerables y no exentas a las que alude su art. 4, a) (claramente referido a la fijación del PVP y no del "precio de adquisición») cuando excluye de aquélla exención general a los «... acuerdos verticales que, directa o indirectamente, por sí solos o en combinación con otros factores bajo control de las partes, tengan por objeto: a) La restricción de la facultad del comprador de determinar el precio de venta, sin perjuicio de que el proveedor pueda imponer precios de venta máximos o recomendar un precio de venta, siempre y cuando éstos no equivalgan a un precio de venta fijo o mínimo como resultado de presiones o incentivos procedentes de cualquiera de las partes...»." 
Esta información periódica a la que puede acceder el franquiciador debe de consistir como mínimo en el nivel de consecución de los objetivos por campaña comercial, los pedidos y recepción de los productos y servicios, la asistencia postventa, el nivel de productos defectuosos, las reservas de suministros que posee, los picos comerciales, las cuentas anuales del franquiciado, las declaraciones tributarias y el pago de los impuestos, etc ${ }^{34}$.

c) Obligaciones de información del franquiciado.

Finalmente, el artículo 545-9.4 de la PALCM establece la obligación del franquiciado de comunicar al franquiciador con la mayor antelación posible las circunstancias que puedan afectar a la actividad comercial, a la imagen y la salvaguarda de la propiedad intelectual de sus productos o servicios, así como al acceso de los consumidores a éstos.

Hay que destacar que si bien en el texto inicial de la PCM esta obligación de información no estaba contemplada, la Sección Segunda, de Derecho Mercantil del Ministerio de Justicia, una vez recibido el dictamen del Consejo de Estado y escuchados los diferentes actores de la distribución comercial, procedió a incluirla.

Esta obligación de suministro de información se encuentra intrínsecamente relacionada con la obligación del franquiciado de comercializar los productos y servicios respetando la marca del franquiciador y que se regula en el artículo 545-9.2 de la PALCM. En este sentido, el franquiciado viene obligado a mantener informado al franquiciador de cualquier circunstancia en su área de influencia que pueda afectar a los bienes y servicios objeto de distribución, todo ello a los efectos de que el franquiciador pueda tomar las medidas oportunas para frenar o minorar cualquier daño que se pudiera estar produciendo a la marca y reputación de los bienes y servicios objeto de distribución.

\section{II.C. Duración y extinción del contrato.}

\section{II.C.1. Régimen general.}

Los artículos 545-18 a 545-23 de la PALCM establecen las normas generales sobre la duración y extinción de los contratos de dis-

34 CALAVIA MOLINERO, José Manuel. "El contrato de distribución en exclusiva". En: Los contratos de distribución comercial. Novedades legislativas y jurisprudenciales. Ed. Tirant lo Blanch, Valencia 2010, pág.81. 
tribución comercial, aplicables, por tanto, a los contratos de franquicia.

La duración del contrato de franquicia es un elemento esencial al tratarse de un contrato de tracto sucesivo y con finalidad de perdurar en el tiempo. Por lo general, los contratos de franquicia suelen establecer plazos de duración determinada de entre cinco, diez o incluso veinte años, pudiendo ser prorrogables en algunos $\operatorname{casos}^{35}$. La duración del contrato vendrá determinada por lo que las partes establezcan, no obstante, la práctica recomienda que como mínimo tenga una duración que permita al franquiciado amortizar las inversiones necesarias para poder ejecutar el contrato.

La PALCM prevé asimismo la posibilidad de que los contratos de franquicia puedan ser suscritos por tiempo indefinido ${ }^{36}$ y permite, según lo dispuesto en el artículo 545-18.2, la posibilidad de que aquellos contratos por tiempo determinado que continúen siendo ejecutados tras la finalización del plazo pactado se conviertan automáticamente en contratos por plazo indefinido.

La distinción entre contratos de franquicia de duración determinada o indeterminada tiene su especial relevancia en el momento de la extinción, siendo en este aspecto donde se ven realmente las diferencias entre una y otra modalidad.

Un contrato de franquicia de duración determinada se extingue cuando llegue a término el plazo establecido por las partes salvo que exista algún tipo de cláusula para prorrogar el mismo o se acuerde entre las partes su renovación con carácter previo a su finalización. En principio, la extinción del contrato por el transcurso del tiempo no da derecho a ningún tipo de compensación, puesto que en virtud de la independencia existente entre las partes y la autonomía de la voluntad, ambos establecen la duración y término del contrato de forma que son conscientes del inicio y final de las obligaciones y derechos que gozan durante un determinado periodo de tiempo.

En lo que respecta a la resolución de los contratos de franquicia por tiempo indefinido, el artículo 545-19 de la PALCM establece un régimen normativo particular tendente a regular el denominado "preaviso ${ }^{37}$, consistiendo éste en una denuncia unilateral del contrato

35 TORRUBIA CHALMETA, Blanca. "El Contrato de Franquicia”. Revista Cuadernos de Derecho y Comercio. N ${ }^{\circ}$ 54, 2010, pág. 322.

36 Según el art. 545-18 de la PALCM, si no se fija una duración determinada se entiende que el contrato es indefinido.

37 VAZQUEZ ALBERT, Daniel. "La terminación de los contratos de distribución: causas y efectos patrimoniales". En: Los contratos de distribución comercial. 
por una de las partes y el cual, de conformidad con lo preceptuado en el artículo 545-19.1 de la PALCM debe de hacerse obligatoriamente por escrito ${ }^{38}$.

El plazo de comunicación del preaviso es una condición sine qua non de la validez del mismo, de forma que permita a la otra parte prepararse para los efectos que va a tener la resolución del contrato ${ }^{39}$, así, de conformidad con lo previsto en el artículo 545-19.2 de la PALCM, el preaviso tiene que ser mínimo de un mes por cada año que haya durado el contrato, con un máximo de 6 meses. En el caso de que el contrato tenga una duración indefinida pero haya estado en vigor por menos de un año, basta con un preaviso de un mes. No obstante, se pueden establecer tiempos superiores de preavisos, pero deben de ser iguales para las partes ${ }^{40}$.

Como regla general el preaviso debe de coincidir con el último día del mes, no obstante, se trata de una norma general que las partes pueden modificar.

El incumplimiento por parte del franquiciador o del franquiciado de los plazos de preaviso dará derecho a la otra parte a exigir una indemnización por los daños y perjuicios que haya sufrido ${ }^{41}$. Esta indemnización podrá comprender no sólo los daños y perjuicios que se hayan ocasionados por la resolución anticipada o sorpresiva del contrato sino también por el lucro cesante, amortización de las inversiones realizadas así como cualquier otro daño y perjuicio sufrido $^{42}$.

Finalmente, junto con el régimen de extinción de los contratos de duración indefinida regulados en el artículo 545-19 de la PALCM, el artículo 545-20, en clara inspiración del régimen de resolución de los contratos previsto en el artículo 1.124 del Código Civil, permite que cualquiera de las partes pueda resolver el contrato como consecuencia de un incumplimiento total o parcial de la otra parte de alguna de sus obligaciones esenciales, en cuyo caso no será necesario

Novedades legislativas y jurisprudenciales. Ed. Tirant lo Blanch, Valencia 2010, págs. 153 y ss.

38 SAP de Madrid de 26 de mayo de 2004, Sección 14ª (AC 2004/1989).

39 GARCÍA HERRERA, Alicia. La duración del Contrato de Distribución Exclusiva. Ed. Tirant lo Blanch, Valencia 2006, pág. 617.

40 Art. 545-19.3 de la PALCM, el cual establece: "Las partes podrán pactar plazos mayores de preaviso, sin que el plazo de preaviso del distribuidor pueda ser inferior, en ningún caso, al establecido para el preaviso del proveedor".

41 STS de 15 de marzo de 2011, Sala de lo Civil, Rec. nº 1463/2007 (RJ 2011/3321).

42 STS de 9 de julio de 2008, Sala de lo Civil, Rec. n. 2343/2001 (RJ 2008/4369).

(c) UNED. Revista de Derecho UNED, núm. 26, 2020 
el preaviso. Asimismo, el artículo 545-20 de la PALCM regula también el derecho de las partes a resolver el contrato en el supuesto que la otra parte hubiera sido declarada en concurso de acreedores $^{43}$, así como resolver en caso de darse otros supuestos de extinción pactados por las Partes.

\section{II.C.2. Indemnización por falta de amortización de inversiones específicas.}

El artículo 545-21 de la PALCM regula el régimen de amortización de inversiones aplicable a la extinción de los contratos de distribución en general, régimen que sería de aplicación en el marco de la PALCM al contrato de franquicia, así, el artículo 545-21.1 de la PALCM regula el derecho del franquiciado a ser compensado por aquellas inversiones no amortizadas en el supuesto de que el franquiciador hubiera resuelto unilateralmente el contrato de franquicia sin haber transcurrido un plazo razonable para la amortización de dichas inversiones.

Estamos ante una indemnización por daños producidos como consecuencia de la inoportuna terminación del contrato por parte del franquiciador, por tanto, no se trata de una indemnización por una resolución abusiva del contrato, sino como consecuencia de la resolución inoportuna del mismo ${ }^{44}$. Asimismo, dado su carácter de resolución inoportuna, estamos ante un supuesto indemnizatorio que no podrá darse en el supuesto de resolución del contrato por expiración del plazo de duración pactado.

43 En estos casos la Ley 22/2003, de 9 de julio, concursal establece al regular los efectos del concurso sobre los contratos con obligaciones reciprocas, como regla general que la declaración del concurso, por ella misma, no afecta a la vigencia del contrato, de forma que las obligaciones pendientes de cumplimiento tanto a cargo del concursado (ya sea el franquiciador o el franquiciado) como de la otra parte, estableciendo como excepción que la administración concursal, en caso de suspensión de las facultades del concursado, o el propio concursado, en el caso de intervención, pueda solicitar al juez la resolución de los contratos si se estimara conveniente para el interés del concurso. En casos de que se lleve a cabo dicha regla general, sobre la posibilidad de solicitar la resolución del contrato, se tienen por no puestas los plazos o clausulas acerca de las motivaciones o indemnizaciones que han de otorgarse o distribuirse entre las partes para tomar el contrato como resuelto o finalizado.

44 MARTÍ MIRAVALLS, Jaume. "Desistimiento unilateral e indemnización por daños en los contratos de distribución. Estudio de la naturaleza jurídica de la indemnización por inversiones no amortizadas." Revista de Derecho Mercantil. $\mathrm{N}^{\circ} 285$, 2012, págs. 95-136. 
En este sentido, para que haya derecho a la indemnización es necesario que existan inversiones amortizables y que dichas inversiones se hubieran realizado como consecuencia de la expectativa generada al franquiciado de desarrollar el negocio de franquicia. Así, el artículo 545-21.2 de la PALCM establece que tendrán la consideración de inversiones específicas aquellas realizadas en cumplimiento o desarrollo del contrato y que no puedan ser aprovechadas de modo real y efectivo. Como ya comentamos anteriormente, estas inversiones son aquellas instruidas y realizadas en interés del negocio principal y que no pueden ser aprovechadas de forma real y efectiva en otros usos, no tienen posibilidad de reventa o que ocasionen una pérdida de forma grave al inversor. A sensu contrario, no tienen esta consideración aquellas inversiones ya amortizadas o que se supone que lo están conforme a la fiscalidad y sus reglas de amortización, así como las inversiones que de forma genérica se realicen ${ }^{45}$.

En cuanto a la cuantificación de la indemnización, tal y como establece el artículo 545-21.4 de la PALCM, ésta alcanzaría no sólo el importe de las inversiones pendientes de amortizar sino inclusive el coste de las indemnizaciones del personal del franquiciado que debiera de ser despedido como consecuencia de la terminación anticipada del contrato de franquicia.

\section{II.C.3. Compensación por clientela.}

El artículo 545-23 de la PALCM regula el régimen de compensación por clientela en el supuesto de resolución del contrato, siendo la acción que produce más pronunciamientos judiciales en el marco de las extinciones de contratos de distribución ${ }^{46}$, no obstante, siendo la más importante, no es la única compensación que el franquiciado puede reclamar, pues como ya vimos anteriormente, éste puede hacerlo por otros conceptos ${ }^{47}$.

45 ZURITA HERRERA, Pedro. "Duración y extinción del contrato de distribución en el Proyecto de Ley del Contrato de Distribución”. Revista de Derecho Patrimonial. $\mathrm{N}^{\circ} 29$, 2012. Ed. Aranzadi, pág. 379.

46 SSTS de 22 de marzo de 1988, Sala de lo Civil (RJ 1988/2224); de 16 de marzo de 2016, Sala de lo Civil, Rec. no 2541/2013 (RJ 2016/858). y de 7 de octubre de 2016, Sala de lo Civil, Rec. $n^{\circ}$ 1627/2014 (RJ 2016/4738), entre otras.

47 Otra de las acciones que son comunes es la reclamación de los descuentos o rappels, esta acción mantiene muchos elementos comunes sobre la acción por compensación por clientela como que se otorgue en base al número de clientes u operaciones efectuadas. No obstante esta acción no tiene por qué darse automáticamente en todos los contratos y de ahí su no inclusión o menor importancia respecto a la compensación por clientela, puesto que este tipo de reclamación solo puede darse 
Así, en lo que respecta a los otros supuestos indemnizatorios que puedan surgir por causa en la resolución anticipada del contrato, la indemnización por clientela se diferencia de la indemnización por falta de amortización de inversiones específicas en el objeto indemnizatorio, mientras que en el primero se indemniza una inversión o gasto realizado por el franquiciado, en el segundo se indemniza por el fondo de comercio generado por el franquiciado y que quedaría a beneficio del franquiciador, no obstante, ambos supuestos indemnizatorios comparten múltiples elementos; como son la previsión o no de las causas o formas contractuales de compensación, el tiempo de duración del contrato, una metodología específica para su cálculo o el aprovechamiento por parte del franquiciador, entre otros ${ }^{48}$.

Como ya adelantamos, se debe de partir del contenido del art. 545-23 de la PALCM, según dicho precepto no es obligatorio que cuando se finalice un contrato de franquicia el franquiciado sea compensado por la clientela que éste hubiera podido generar, pues para que sea compensado deben de haberlo pactado las partes. Como el resto de cláusulas del contrato, la cláusula de compensación por clientela debe de redactarse o establecerse de forma clara, puesto que en el caso de no presentar una interpretación literal y clara no es posible concluir que el franquiciado deba de ser compensado de manera automática ${ }^{49}$.

Esta falta de compensación automática se basa en la independencia y riesgo que las partes asumen al firmar el contrato, el franquiciador no remunera al franquiciado, sino que éste gana dinero con su actividad, en la que asume los riesgos propios de la empresa. Puede así concluirse que la actividad del franquiciado beneficia al franquiciador, pero sin empobrecimiento propio. Sucede, como en otros muchos supuestos, que una determinada actividad, además de enriquecer al que la realiza, beneficia indirectamente a terceros, pero sin empobrecimiento correlativo del primero, en cuyo caso no ha lugar a indemnización, porque la medida de ésta es la del empobrecimiento propio y no la del enriquecimiento ajeno.

en ciertos tipos de contratos en los que exista una distribución en exclusiva, es decir, en aquellos en que el franquiciado goce de ciertas ventajas o descuentos o que le otorguen ingresos o beneficios como rappels, que en caso de incumplimiento puede reclamar.

48 GARCÍA HERRERA, Alicia. La duración del Contrato de Distribución Exclusiva. Ed. Tirant lo Blanch, 2006, págs.780 y ss.

49 STS de 7 de octubre de 2016, Sala de lo Civil, Rec. n ${ }^{\circ} 1627 / 2014$ (RJ 2016/4738). 
De forma excepcional, el artículo 545-23.2 de la PALCM permite compensar los aumentos de clientela que el franquiciado hubiera producido y que quedaran a beneficio del franquiciador una vez extinguido el contrato ${ }^{50}$, este precepto legal es una plasmación de la doctrina jurisprudencial consolidada que reconoce puntual y casuísticamente una indemnización por daños y perjuicios y que está fundada en la doctrina del enriquecimiento injusto o sin causa en la medida que ésta se acredite y siempre que concurra alguna de las circunstancias expuestas en el art. 545-23.2 de la PALCM, que aplicadas al contrato de franquicia serían:

a) Que el franquiciado haya incrementado de manera sustancial el tipo de operaciones o el número de clientes y sea razonable presumir que el franquiciador puede seguir obteniendo ventajas sustanciales de esta clientela;

b) Que el franquiciado haya facilitado al franquiciador un listado de clientes que genera al franquiciador una ventaja competitiva;

c) Que exista un pacto por el cual el franquiciado, una vez extinguido el contrato, no pueda hacer competencia al franquiciador o al nuevo franquiciado.

Las dos primeras circunstancias son clausulas normativas abiertas y que requieren un análisis de los elementos entre el comienzo y final del contrato. El tercero de los casos requiere de una cláusula de prohibición expresa en el contrato de dedicación a la misma actividad.

La norma no establece que para que el franquiciado sea compensado se deban de dar una sola de las circunstancias pudiéndose darse todas en un contrato. Pero por muchas que se den al mismo tiempo esto no quiere decir que la indemnización por clientela vaya a ser mayor en ese caso concreto, esto es debido a que las normas de valoración de la clientela deberán de adecuarse al caso concreto.

50 BENEDITO TORRECILLA, Victor. "Los aspectos económicos de las indemnizaciones por extinción del contrato de distribución". En: Los contratos de distribución comercial. Novedades legislativas y jurisprudenciales. Ed. Tirant lo Blanch, Valencia 2010, págs. 199 y ss; y DEVAUREIX, Jean, PATIÑO RIVEIRA, Natalia y PÉREZ FERNÁNDEZ, Patricia. "Dos visiones sobre la Indemnización por Clientela en los Contratos de Distribución. El Proyecto de Ley de Contratos de Distribución 121/000138". En: La Reforma de los Contratos de Distribución comercial. Ed. La Ley, Madrid 2013, págs. 521 y ss. 


\section{EL CONTRATO DE MASTER FRANQUICIA EN LA PROPUESTA DE ANTEPROYECTO DE LEY DE CÓDIGO MERCANTIL.}

Por último, es de destacar la falta de regulación que la PALCM realiza respecto del contrato de master franquicia, contrato que evidentemente tiene una estrecha relación con el contrato de franquicia pero del cual difiere puesto que el objeto principal del contrato de master franquicia consiste en concluir contratos de franquicia con terceros respecto de los cuales el master franquiciado asumirá las funciones de franquiciador ${ }^{51}$.

De esta manera, como consecuencia de la falta de regulación del contrato de master franquicia en la PALCM, nos encontraremos con que dicho contrato continuará manteniendo su característica de atípico, pudiendo las partes regular aquellos términos y condiciones que consideren oportunos y sin que la regulación que para los contratos de distribución en general se prevé en la PALCM los pueda limitar.

No obstante, no debemos de perder de vista que dada su condición de contrato mercantil, sí será de aplicación al contrato de master franquicia la regulación que de las obligaciones y de los contratos mercantiles en general se prevé en el Libro IV de la PALCM.

A la vista de lo anterior, si bien es coherente que el contrato de master franquicia no se regule junto con los restantes contratos de distribución en la PALCM, no se justifica su falta de regulación en la propuesta normativa pues nos encontramos con un contrato de influencia muy relevante en el ámbito de la franquicia y, además, dado su carácter eminentemente mercantil justificaría su regulación.

\section{CONCLUSIONES.}

La propuesta de regulación del contrato de franquicia prevista en la PALCM, sin ser todo lo exhaustiva que a nuestro juicio debería de ser, supone un importante avance en el desarrollo de un marco normativo en nuestro país para dicho contrato y que resulta necesario para dotar de mayor seguridad jurídica al sector de la franquicia.

51 NAVARRO MÁÑEZ, Miguel y ARRIBAS OCHOA, Carlos. "La Aplicación a la Franquicia del Régimen Propuesto para el Contrato de Distribución: Una Valoración Crítica”. En: La reforma de los contratos de distribución comercial. Ed. La Ley, Madrid 2013, pág. 103. 
No obstante, la regulación prevista en la PALCM tiene importantes lagunas que deben de ser rectificadas en su trámite de desarrollo legislativo, pues de acuerdo con la actual regulación surgen importantes dudas al respecto del alcance de su ámbito de aplicación al contrato de franquicia y si ésta regulación se limitaría únicamente a aquellos contratos de franquicia comercial que implican una función de distribución.

En lo que respecta al régimen de perfeccionamiento del contrato de franquicia previsto en la PALCM, por un lado, se echa en falta la obligatoriedad de que los contratos de franquicia sean recogidos en forma escrita, mientras que, por otro lado, en lo que respecta a la información precontractual, si bien la información que deben de suministrarse las partes con anterioridad a la conclusión del contrato resulta bastante exhaustiva desde el punto de vista de la función de distribución, debe de tomarse en cuenta la necesidad de adaptar la misma a las necesidades del contrato de franquicia y, en particular, a lo establecido en el artículo 62.2 de la LOCM y el artículo 3 del Real Decreto 201/2010, de 26 de febrero, por el que se regula el ejercicio de la actividad comercial en régimen de franquicia.

Sobre el régimen de obligaciones de las partes dispuesto en la PALCM y aplicable al contrato de franquicia, entendemos que éste régimen resulta del todo insuficiente puesto que la regulación prevista en los artículos 545-7 a 545-9 sería de aplicación en su mayor parte a aquellos contratos de franquicia que tengan una función de distribución, dejándose únicamente como regulación de obligaciones específicas del contrato de franquicia lo dispuesto en el artículo 545-17 de la PALCM y cuya regulación es del todo insuficiente.

En cuanto al régimen de duración y extinción del contrato regulado en la PALCM, se ha producido un importante avance al reconocerse al franquiciado derechos compensatorios en caso de resolución anticipada del contrato y sujeto al cumplimiento de determinados requisitos, materia que si bien nuestra jurisprudencia ya venía reconociendo, permite dotar de mayor seguridad jurídica a las relaciones de franquicia y así evitar la alta litigiosidad existente al respecto a día de hoy.

Finalmente, se echa en falta en la PALCM una propuesta de regulación del contrato de master franquicia dada la importancia que dicho contrato tiene en la práctica habitual y su carácter mercantil. 
